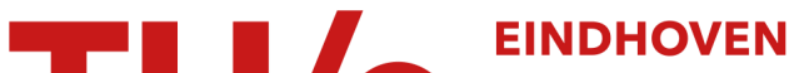 \\ UNIVERSITY OF \\ TECHNOLOGY
}

\section{Strain path dependence of flow curves}

\section{Citation for published version (APA):}

Sillekens, W. H., Dautzenberg, J. H., \& Kals, J. A. G. (1991). Strain path dependence of flow curves. CIRP Annals, 4O(1), 255-258. https://doi.org/10.1016/S0007-8506(07)61981-7

DOI:

10.1016/S0007-8506(07)61981-7

Document status and date:

Published: 01/01/1991

\section{Document Version:}

Publisher's PDF, also known as Version of Record (includes final page, issue and volume numbers)

\section{Please check the document version of this publication:}

- A submitted manuscript is the version of the article upon submission and before peer-review. There can be important differences between the submitted version and the official published version of record. People interested in the research are advised to contact the author for the final version of the publication, or visit the $\mathrm{DOI}$ to the publisher's website.

- The final author version and the galley proof are versions of the publication after peer review.

- The final published version features the final layout of the paper including the volume, issue and page numbers.

Link to publication

\section{General rights}

Copyright and moral rights for the publications made accessible in the public portal are retained by the authors and/or other copyright owners and it is a condition of accessing publications that users recognise and abide by the legal requirements associated with these rights.

- Users may download and print one copy of any publication from the public portal for the purpose of private study or research.

- You may not further distribute the material or use it for any profit-making activity or commercial gain

- You may freely distribute the URL identifying the publication in the public portal.

If the publication is distributed under the terms of Article $25 \mathrm{fa}$ of the Dutch Copyright Act, indicated by the "Taverne" license above, please follow below link for the End User Agreement:

www.tue.nl/taverne

Take down policy

If you believe that this document breaches copyright please contact us at:

openaccess@tue.nl

providing details and we will investigate your claim. 


\title{
Strain Path Dependence of Flow Curves
}

\author{
W. H. Sillekens, J. H. Dautzenberg (2), J. A. G. Kals (1), Laboratory for Forming Technology, \\ Eindhoven University of Technology \\ Received on January 15, 1991
}

\begin{abstract}
This paper deals with the changes in flow behaviour, resulting from abrupt changes in the strain path. The transitions tension-to-compression, tension-to-torsion and torsion-to-tension were investigated, using the plastic strain at the transition as a parameter. Three materials were selected for the experiments: CuZn37 brass, C22 steel and Armco steel.

Results of the combined tests are presented and compared with the corresponding standard flow curves (from compression, tension and torsion test). A conventional flow function (Hollomon) is accommodated to record the observed flow curve changes. Metallurgical backgrounds are considered.
\end{abstract}

KEY WORDS: forming, flow stresses.

\section{Introduction}

The flow curve (stress-strain curve) of a metal depends not only on the temperature and the strain rate, but aiso on the strain path. A well-known expressicn of this strain path dependency exhibits at a total reversal in straining direction; this is called the "Bauschinger effect". The influence of the strain path on the flow behaviour, however, is not limited to this single illustration but is more comprising.

The study of these phenomena is not merely theoretical: many forming processes, more or less, involve deflections of a plain strain path. Changes in strain path which lead to a flow stress drop or a decrease in strain hardening are unfavourable since they may cause unstable flow, strain concentration and even material failure. Several investigations have been done hitherto, either from a thecreticalmetallurgical [8] or from a more practical point of view [4,9]. Yet, a quantitative description for use in metal forming calculations is, to the knowledge of the authors, not available.

In the present stucy, the flow curve changes resulting from abrupt changes in the strain path were investigated. These abrupt changes were actualized by subjecting specimens successively to two different standard material tests. In this way three types of combined tests were realized: "tension-compression", "tension-torsion" and "torsion-tension" tests. The equivalent strain at the transition (pre-strain $\bar{\epsilon}_{0}$ ) was varied.

The object of this work was to record the results of the combined tests in accommodated flow functions, as opposed to previous work which did only record some typical changes in flow behaviour [7]. In section 3 of this paper it will be shown that the results can be expressed as parameter changes in the Holiomon flow function. Preceding to this, the experimental proceciure will be discussed.

\section{Experimental procedure}

An investigation into the strain path dependency of flow curves must be supported by a careful experimental set-up. The combined tests were, as compared to standard material tests, rather involving. This will be discussed here briefly.

Tension-compression tests. Pre-straining was done by subjecting cylindrical test bars to a tensile load. Next, compression specimens were machined from the (uniformly) pre-strained sections. These were designed as Rastegaev specimens (initially $\$ 12 \mathrm{~mm}$ ) to maintain a uni-axial stress state and uniform deformation during testing [6]. The flow curves were computed from the measured quantities: compressive force and specimen diameter.

Tension-torsion tests. For every test, two cylindrical test bars were strained in tension to the same pre-strain. These specimens were identical, except for the diameter which was slightly different (initially $\phi 8.0$ and $\phi 6.4 \mathrm{~mm}$ ). The pre-strained bars were used to perform a differential torsion test; flow stress values were calculated from the difference in required moments to twist the respective specimens (e.g. [2]; von Mises yield criterion assumed). In this manner no presupposition of a flow function was necessary.

Torsion-tension tests. For these tests a similar approach as in the iension-torsion tests was adopted. A pair of test bars of different diameter (see above) was twisted to a corresponding level of torsional pre-strain, and subsequently was used to perform a differential tension test. The flow curve thus was deduced from the imaginary tube, obtained by "subtraction of the two specimens". Benefit of this approach was that the torsional pre-strain was (nearly) constant for the considered "tube". The respective tensile forces and diameter changes were measured.

To outline the results of the combined tests, the corresponding standard tests (compression, tension and torsion tests) also were done.

The tests were done at room temperature and in a quasi-static fashion; the range of equivalent strains which was explored was confined globally to: $0<\bar{\epsilon}<1$.

Three materials were used for the experiments: CuZn37 brass (DIN indication 2.0321), C22 steel (DIN indication 1.0402) and Armco steel (trade name). For every material, the specimens were machined from the same rod $(\phi 20 \mathrm{~mm})$ and were annealed to obtain a homogeneous structure. This was checked both by hardness measurements and microscopic examination in longitudinal and transverse direction: no significant differences revealed.

\section{Results}

In this section the results of the combined tests are presented by means of some examples and by a suitable characterization of the obtained flow curve changes. To start with, however, the results of the standard tesis are presented.

3.1. Standard flow curves

For each material the standard tests were done in triplicate. The results of Armco steel are shown in figure 1. For tension, the employed strain range was extended to the necking range by using the Bridgman correction [1]; this required the additional measurement of profile radii. These tension tests were done using solid specimens (initially $\Phi 7 \mathrm{~mm}$ ).

The experimental data were processed using a PC-program for fitting of flow functions in a least-squares sense [5]. The Hollomon 


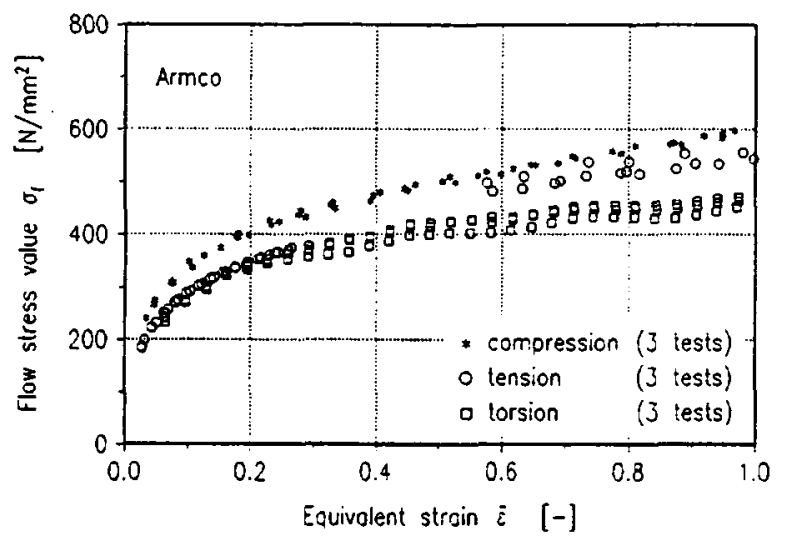

Figure 1 Standard flow curves of Armco steel

Table 1 Characterization of standard flow curves

\begin{tabular}{ll||c|c|c} 
& $\sigma_{f}=\mathrm{C} \cdot \bar{\epsilon}^{n}$ & $\begin{array}{c}\text { compres- } \\
\text { sion }\end{array}$ & tension & torsion \\
\hline \multirow{2}{*}{ CuZn37 } & $C\left[\mathrm{~N} / \mathrm{mm}^{2}\right]$ & 750 & 759 & 477 \\
& $n[\cdot]$ & 0.504 & 0.503 & 0.403 \\
\hline \multirow{2}{*}{$\mathrm{C22} \quad \mathrm{C}\left[\mathrm{N} / \mathrm{mm}^{2}\right]$} & 832 & 756 & 670 \\
& $n[-]$ & 0.197 & 0.232 & 0.172 \\
\hline \multirow{2}{*}{ Armeo } & $C\left[\mathrm{~N} / \mathrm{mm}^{2}\right]$ & 595 & 560 & 471 \\
& $n[\cdot]$ & 0.250 & 0.292 & 0.214
\end{tabular}

flow function ( $\sigma_{f}=C \cdot \vec{\epsilon}^{n}$ ) showed good results for all three materials and features a convenient characterization with only two parameters. Obtained coefficients of correlation A were lowest for the torsion tests, yet in every case $R \geq 0.9895$.

Each flow curve thus is characterized by a characteristic stress $\mathrm{C}$ and a strain hardening exponent $n$. The average values are shown in table 1. All three materials showed discrepancies between the distinct standard flow curves; these were most pronounced for CuZn37 brass.

3.2. Tension-compression flow curves

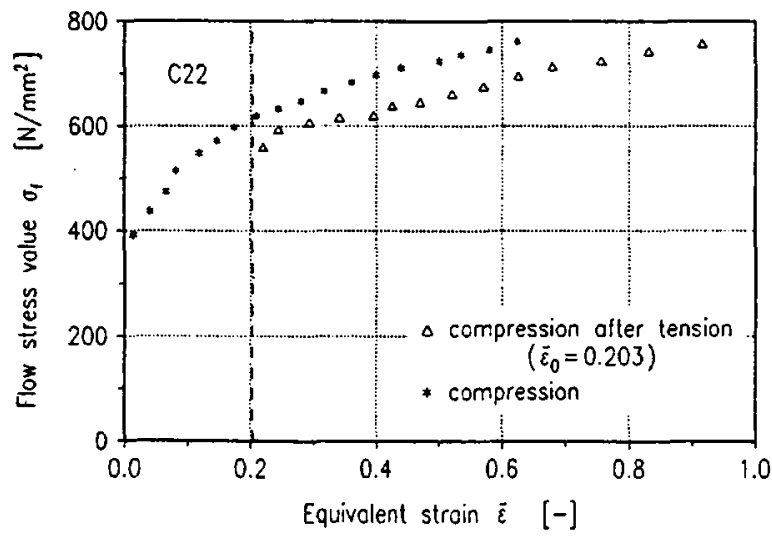

Figure 2 Examples ot flow curves (tension-compression)

An example of a compression flow curve after pre-straining in tension is shown in figure 2; a corresponding standard compression flow curve is also included. This is a classical illustration of the Bauschinger effect.

It was found that the compression branches of the obtained flow curves could be described by an accommodated form of the
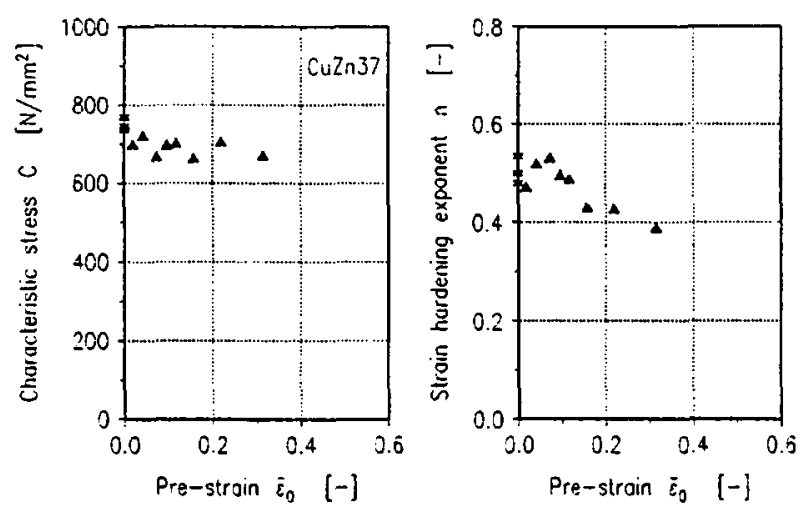

Figure 3 Characterization of flow behaviour (compression atter tension)

Hollomon flow function. Here. the characteristic stress $C$ and the strain hardening exponent $n$ are considered not to be constant, but to be interrelated with the pre-strain $\bar{\epsilon}_{0}$. Or: $\sigma_{f}=C \cdot \bar{\epsilon}^{n}$, in which $C=C\left(\bar{\epsilon}_{0}\right)$ and $n=n\left(\bar{\epsilon}_{0}\right)$. The symbol $\bar{\epsilon}$ then denotes the accumulated equivalent strain (sum of the pre-strain and the current strain). In this manner the results could be recorded satisfactorily; they are represented in the figures 3,4 and 5 . Matching values from the standard compression tests are reproduced on the ordinates of the graphs.

\subsection{Tension-torsion flow curves}

In figure 6, an example of a flow curve from torsion after prestraining in tension is shown, accompanied by corresponding standard flow curves.

The torsion branches of the obtained flow curves could be
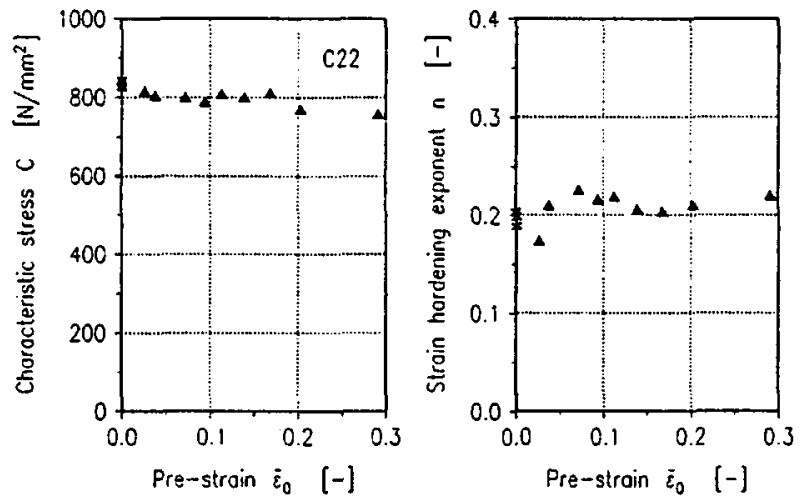

Figure 4 Characterization of flow behaviour (compression after tension)
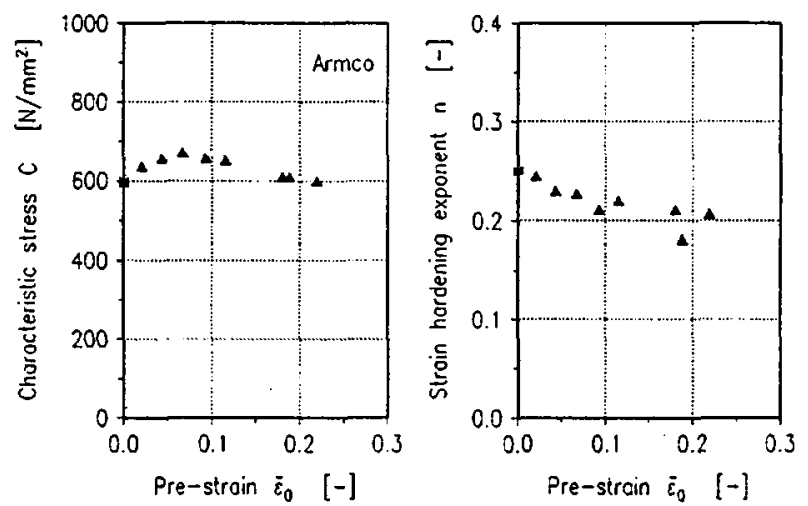

Figure 5 Characterization of flow behaviour (compression atter tension) 


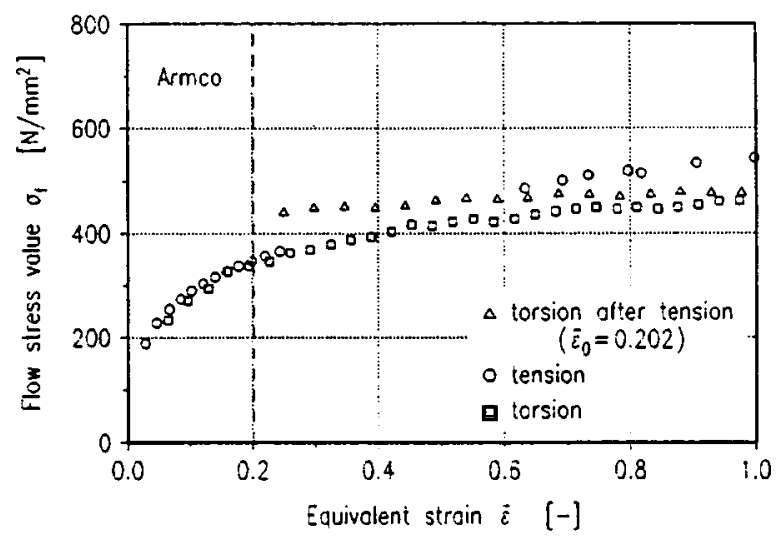

Figure 6 Examples of flow curves (tension-torsion)

described by the accommodated Hollomon flow function in the way depicted above. The characteristic stress and the strain hardening exponent, thus determined, are shown as a function of the pre-strain in the figures 7,8 and 9 for the distinct materials. Matching values for torsion are included. These flow curve changes exhibit by a decrease in $\mathrm{n} ; \mathrm{C}$ aoproximately remains constant as compared to the values for simple torsion.

\subsection{Torsion-tension flow curves}

In the torsion-tension tests, the strain range was restricted by the occurence of necking of the sfecimens. CuZn37 brass showed the largest employable range, which is connected with its high strain hardening ability.

An example of a tension flow curve after torsional pre-straining is shown in figure 10, together with matching standard flow curves.
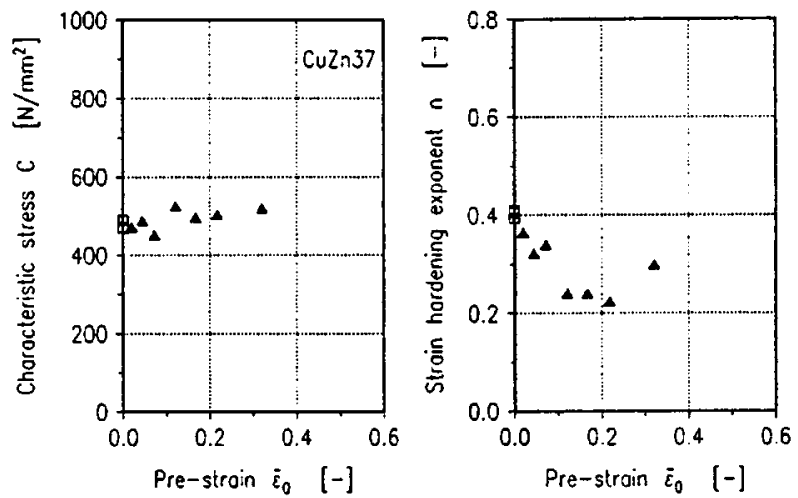

Figure 7 Characterization of flow behaviour (torsion after tension)
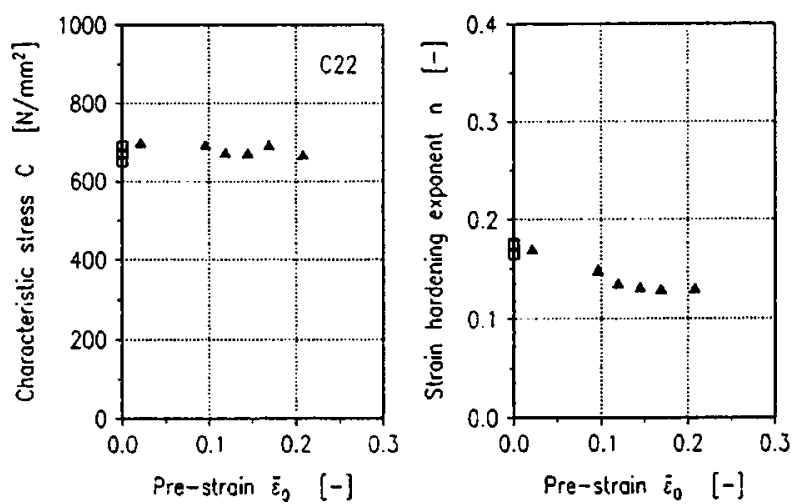

Figure 8 Characterization of flow behaviour (torsion after tension)
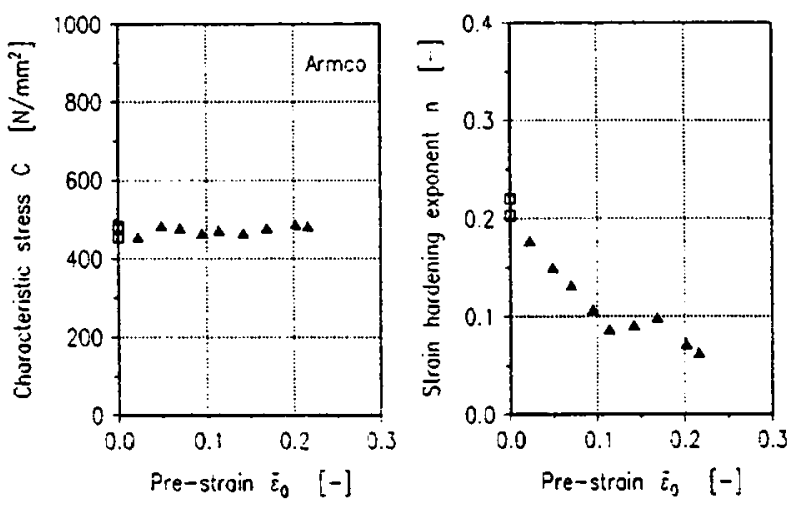

Figure 9 Characterization of flow behaviour (torsion after tension)

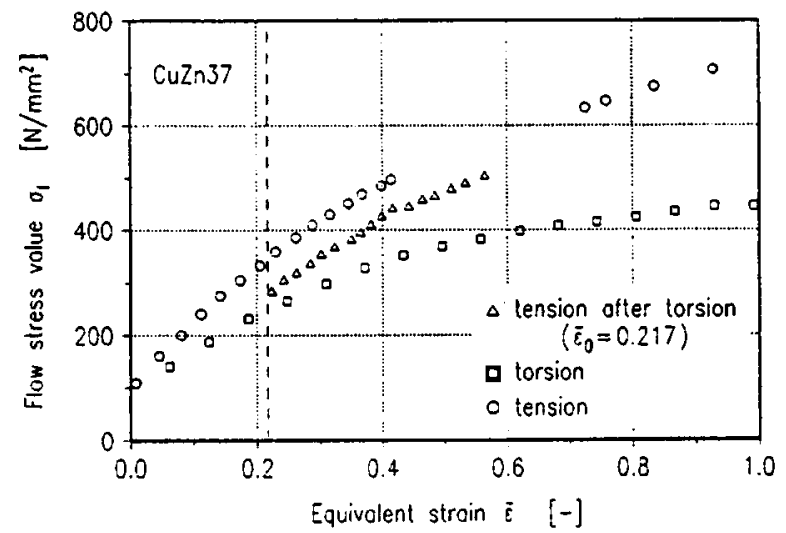

Figure 10 Examples of flow curves (torsion-tension)
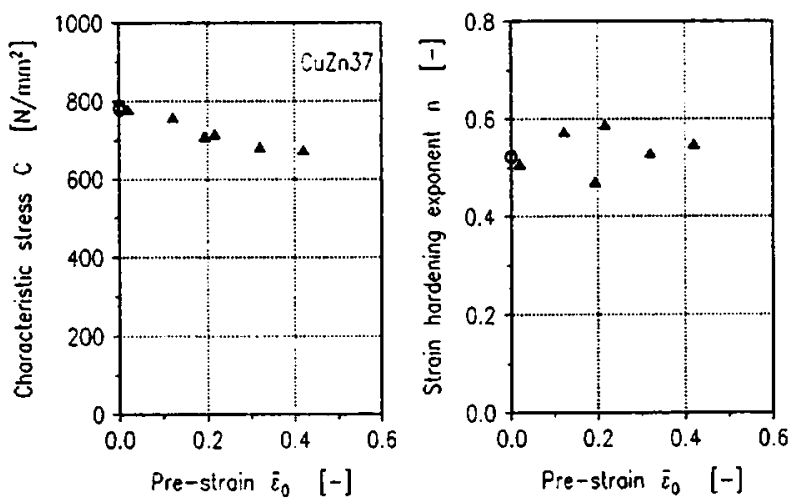

Figure 11 Characterization of flow behaviour (tension after torsion)

For CuZn37 brass it was possible to fit the tension branches of the obtained flow curves to the flow function as described before. This yielded the results shown in figure 11. The values for simple tension (uniform straining range) are added. Obviously, $\mathrm{C}$ decreases as a function of the pre-strain, whereas $n$ does not show a clear dependency.

The proposed flow function, unfortunately, was not apt to describe the results obtained from the steels $\mathrm{C} 22$ and Armco. This shows from the figures 12 and 13, in which some examples are reproduced. Both steels show a similar behaviour: pre-straining in torsion leads to a significant hardening of the material in a subsequent tensile deformation mode. 


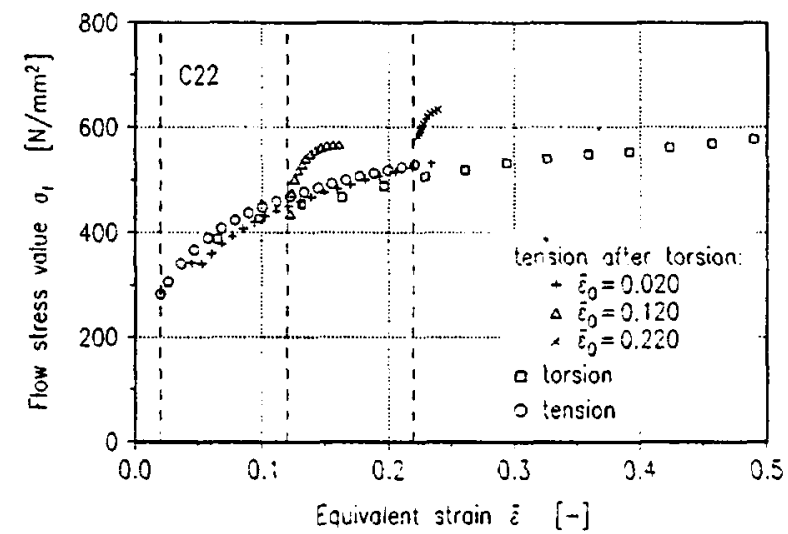

Figure 12 Examples of flow curves (torsion-tension)

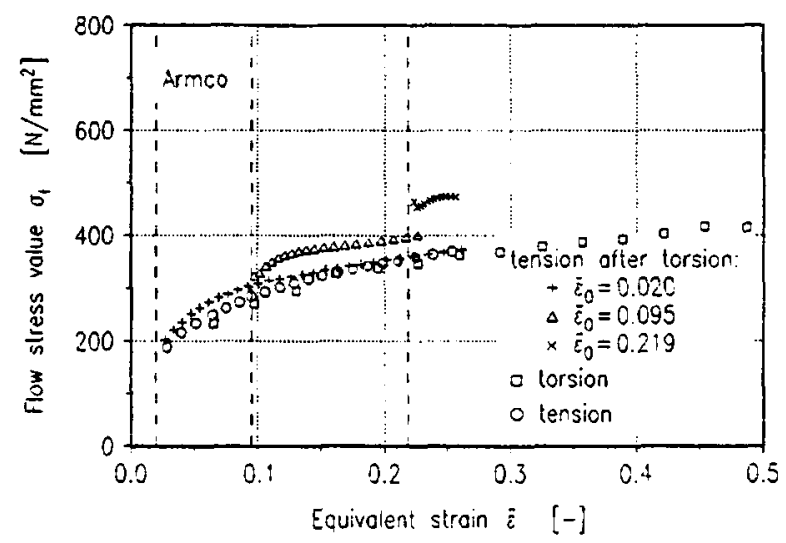

Figure 13 Examples of flow curves (torsion-tension)

\section{Discussion}

The compression, tension and torsion tests yielded different How curves. This may originate from a number of different causes. that can be classified with respect to their backgrounds in experimental, theoretical and metallurgical causes. Requirements appointed by the first category include a proper experimental set-up. the use of calibrated test-equipment and uniform properties of the test-materials. These were attained to as much as possible in this work. The second category involves the assumption of a yield criterion (torsion) and the utilization of a correction for necking in tension. Metallurgical backgrounds, nevertheless, are considered to be decisive for the differences in the obtained standard flow curves. This is supported by several previous investigations. Differences between the flow curves from uni-axial testing and torsion can be explained from the development of both different textures and different microstructures (e.g. of dislocations) in the deforming material $[2,10\}$. These effects lead to flow curves which diverge with strain and from which the torsion curve is positioned lower. Differences between flow curves from compression and tension tests can be explained from an influence of the hydrostatic stress component on the actual flow stress value [3]. In this view, a hydrostatic pressure (as in compressive testing) leads to higher flow stresses. Hence, the compression, tension and torsion How curves may deviate, depending on the material's features.

Metallurgical backgrounds of the Bauschinger effect also are established more or less (e.g. [8]). Here, a lower yield stress value in reverse straining direction basically is explained from a larger motional freedom of dislocations, as compared to the forward direction. This lower yield stress may be representative for constructive use of cold formed parts.

In the present study, however, not the initial yielding but the flow stress behaviour at considerabie strains was empnasized. This can be estimated in a global way from the proposed characierization.

\section{Conclusion}

The strain path may have a significant influence on the flow behaviour. In a first approach, this can be consiciered by basing calculations on the flow curve obtained from a test resembling the actual forming process, for example a torsion test for blanking and a compression test for rolling.

The proposed description of the flow surve changes, resulting from changes in the deformation mode, is ment to be a first impulse to quantify these effects. Possible applications may include the forming processes which involve strong deflections of a plan strain path, such as reverse bending and can extrusion.

Acknowledgement - The authors are indebted to Mr. J.A.A.M. Jongeneien, who performed the experiments in the context of his masters stucy.

\section{References}

[1] Bridgman P.W., 1952,

"Studies in Large Plastic Flow and Fracture",

McGraw-Hill, NewYork Londcn.

[2] Canova G.R., Shrivastava S., Jonas J.J., G'Sell C., 1982, "The Use of Torsion Testing to Assess Material Formability", Formability of Metallic Materials - 2000 A.D., ASTM STP 753: 189.210.

[3] Herbertz R., Wiegeis H., 1980

"Der Unterschied zwischen Zug- und Druckfließkurve, geceutet durch den hydrostatischen Druckeinfluß", Archiv für das Eisenhüttenwesen, 51: 413-416.

(4) Huml P., 1984,

"Utilization of Flow Stress in Metal Forming Calculations", Annals of the CIRP, 33/1: 147-149.

[5] Liempd J.H. van, Dautzenberg J.H., Kals J.A.G., 1988, "Een dataverwerker voor vloeiparameters", MB Produktietechniek, 54: 374-379 (in Dutch).

[6] Pöhlandt K., 1986, "Werkstoffprüfung für die Umformiechnik", Springer-Verlag, Berlin Heidelberg

[7] Sillekens W.H., Dautzenberg J.H., Kals J.A.G., 1988, "Flow Curves for C45 Steel at Abrupt Changes in the Strain Path",

Annals of the CIRP, 37/1: 213-216.

[8] Sowerby R., Uko D.K., Tomita Y., 1979,

"A Review of Certain Aspects of the Bauschinger Effect in Metals",

Materials Science and Engineering, 41: 43-58.

[9] Thomsen E.G., 1983,

"What Stress-Strain Curve shall I use?",

Proceedings of the NAMRI, 11: 157-161.

[10] Witzel W., Haeßner F., 1987,

"Zur Vergleichbarkeit von Werkstoffzuständen nach Dehnen, Stauchen und Tordieren",

Zeitschrift für Metallkunde, 78: 316-323. 